\title{
HIF in the heart: development, metabolism, ischemia, and atherosclerosis
}

\author{
Andrew Kekūpa‘a Knutson, Allison L. Williams, William A. Boisvert, and Ralph V. Shohet \\ Center for Cardiovascular Research, John A. Burns School of Medicine, University of Hawaii, Honolulu, Hawaii, USA
}

\begin{abstract}
The heart forms early in development and delivers oxygenated blood to the rest of the embryo. After birth, the heart requires kilograms of ATP each day to support contractility for the circulation. Cardiac metabolism is omnivorous, utilizing multiple substrates and metabolic pathways to produce this energy. Cardiac development, metabolic tuning, and the response to ischemia are all regulated in part by the hypoxia-inducible factors (HIFs), central components of essential signaling pathways that respond to hypoxia. Here we review the actions of HIF1, HIF2, and HIF3 in the heart, from their roles in development and metabolism to their activity in regeneration and preconditioning strategies. We also discuss recent work on the role of HIFs in atherosclerosis, the precipitating cause of myocardial ischemia and the leading cause of death in the developed world.
\end{abstract}

Hypoxia-inducible factor 1 (HIF1) is the central actor of an ancient, highly conserved pathway that responds to low-oxygen conditions. This transcription factor is composed of two subunits: constitutively expressed HIF1 $\beta$ and oxygen-sensitive HIF1 $\alpha$ (1). In normoxic conditions, the HIF prolyl hydroxylases (PHDs) and asparaginyl hydroxylase (Factor Inhibiting HIF or $\mathrm{FIH}$, respectively) modify residues on HIF1 $\alpha$ that target the protein for degradation and prevent its transcriptional activity $(2,3)$. During hypoxia, these posttranslational modifications are limited, allowing HIF1 $\alpha$ to enter the nucleus, dimerize with HIF1 $\beta$, and bind to genomic hypoxia response elements to promote transcription. Another HIF isoform, HIF $2 \alpha$, senses oxygen and plays a more restricted, albeit important role, especially in the vasculature (4). Less is known about the final member, HIF3 $\alpha$; analysis of this isoform has been complicated by multiple variants encoded from the Hif $3 a$ locus (i.e., NEPAS and IPAS). Additionally, full-length HIF $3 \alpha$ lacks a C-terminal transactivation domain but still dimerizes with HIF1 $\beta$, thereby acting as a negative regulator of HIF1 and HIF2 activity (5).

The heart depends on oxidative metabolism to produce the large amounts of ATP required to sustain contractility. It is exquisitely sensitive to hypoxia, and as a result, cardiac ischemia is the most common cause of death in the developed world. Beyond their systemic roles in oxygen delivery, through erythropoiesis and angiogenesis, HIF-regulated pathways help to protect the heart against hypoxia, tuning the balance of metabolic pathways to provide ATP and activating cell-survival pathways. HIF has other important roles in the heart, directing embryonic development and response to limited oxygen delivery caused by coronary disease. It even plays a role in the progression of atherosclerotic arterial disease that underlies ischemia in many vascular beds,

Authorship note: AKK, ALW, WAB, and RVS contributed equally to this work. Conflict of interest: The authors have declared that no conflict of interest exists. Copyright: @ 2021, American Society for Clinical Investigation.

Reference information: J Clin Invest. 2021;131(17):e137557.

https://doi.org/10.1172/JCl137557. especially the heart. This Review examines what we have learned about the pleiotropic role of HIF in the heart, touching especially on its participation in cardiac development, metabolic response to stress, and atherosclerosis.

\section{The HIF pathway in heart development}

The heart is the first organ to form in the embryo, and its development is necessary for maturation of a working vasculature and formation of other organs. Numerous factors are responsible for the specification and maturation of cardiac cells, including transcription factors (e.g., NKX2.5, TBX, GATA4, MESP1), morphogens (e.g., BMP4, FGF, TGF- $\beta$ ), and epigenetic mechanisms (e.g., DNA methylation) $(6,7)$. Together, these pathways give rise to numerous heart cell types and lineages by initiating specific transcriptional programs (8). Studies over the past 25 years have shown important roles for oxygen and the HIF pathway during embryonic development, particularly in heart morphogenesis, with a still-improving mechanistic understanding (9-11).

In mice, heart development begins at embryonic day 7.5 (E7.5) with formation of the cardiac crescent and is largely complete by E15 (Figure 1A). During this time, localized regions of hypoxia are observed throughout the embryo, and the stabilization of HIFs tracks with these areas (12). The earliest evidence of nuclear HIF1 $\alpha$ in the developing heart is at E8.5 (13), although it is likely stabilized even earlier in newly formed cardiac precursors. By E9.5, HIF1 $\alpha$ is found in the myocardium of the outflow tract and the nascent ventricular and atrial chambers $(14,15)$. From E10.5 to E12.5, HIF1 $\alpha$ becomes restricted to the compact myocardium but is absent in the forming trabeculae, endocardium, and epicardium. By E14.5, once septation and chamber formation have occurred, HIF1 is no longer detectable in most of the heart but persists in the interventricular septum (15). Little has been published regarding HIF2 $\alpha$ protein in the embryonic heart; however, Hif2a mRNA is detected in cardiac tissues at E9 (16). $H$ if $3 a$ does not appear to be expressed in the embryonic heart, although a splicing variant of Hif $3 a$, called Nepas, is found in the late embryonic and early postnatal heart (17). 
A

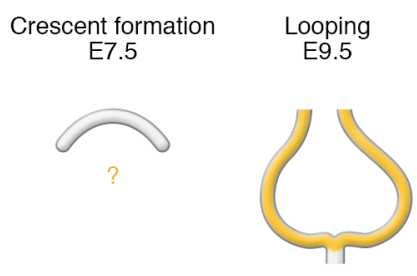

HIF expression

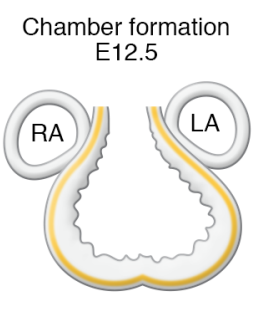

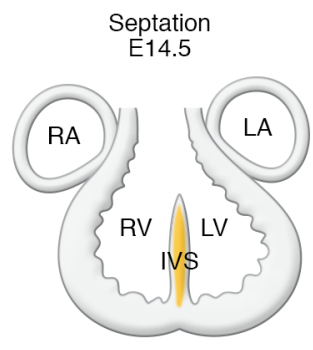

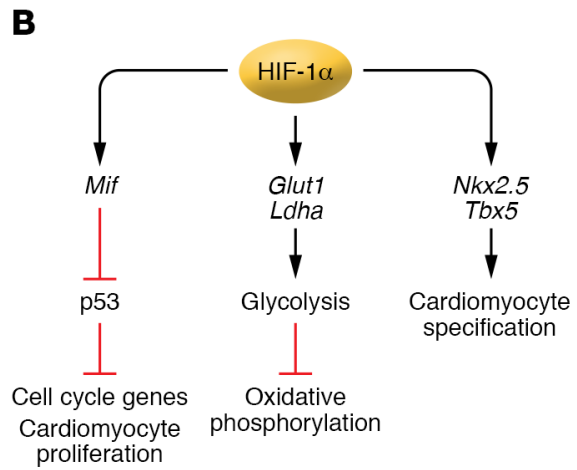

Figure 1. HIF1 expression and function in the developing mouse heart. (A) Mouse heart development occurs over a period of 7 days, beginning with formation of the cardiac crescent, followed by looping, chamber formation and trabeculation, and finally septation. HIF1 $\alpha$ stabilization has been detected at E9.5 in the nascent chambers and outflow track and then becomes restricted to the compact myocardium at E12.5. By E14.5, HIF1 $\alpha$ is restricted to the interventricular septum (IVS). (B) Possible targets and functions of HIF1 during heart embryogenesis. HIF1 is thought to promote cardiomyocyte proliferation, glycolysis, and cardiomyocyte specification in embryonic cardiomyocytes. A switch from glycolysis to oxidative phosphorylation is dependent on HIF1 $\alpha$ compartmentalization in different regions of the heart over time. LV, left ventricle; RV, right ventricle.

HIF-regulated transcription is necessary for important cardiac developmental events including septation $(14,18)$ and trabeculation (15). Embryos lacking Hifla arrest at E10 with small hearts and a hypocellular myocardium (19-21). The range of cardiac abnormalities with Hifla deletion is broad and is influenced by the specific allele and mouse genetic background (ref. 22 and Table 1). Homozygous deletion of the Arnt gene, encoding HIF1 $\beta$, also results in embryonic lethality at E10, with placental defects that may contribute to heart deformities $(23,24)$. Mice lacking Hif2a (also known as Epas1) either arrest in embryogenesis or survive to adulthood with multiple organ pathologies, again depending on the allele used and the mouse background (25-27). Hif3a deletion results in right ventricle hypertrophy, although this may arise from defects in lung remodeling, with the major player being NEPAS rather than full-length HIF3 $\alpha$ (17). Stabilization of HIF1, through deletion of Phd2, can also have deleterious effects on heart development (28). As with Hiflb mutations, these heart defects may be partly due to defects in placenta development and subsequent oxygen deprivation of the embryo. CITED2, a negative transcriptional regulator of HIF1 $\alpha$, is also important for cardiac development $(29,30)$.
The confounding effects of deleting HIF genes in the entire embryo can be avoided by the use of tissue-specific conditional knockouts (Table 2). The earliest conditional knockout of Hifla deletes Hifla in the embryonic mesoderm at E6.5 using Mesp1-Cre. Only half of Hifla $a^{f / 4}$ Mesp1-Cre ${ }^{+}$embryos survived to E17.5, and heart abnormalities were observed in a third of surviving animals (31). In the same study, using an Nkx2.5-Cre line, which deletes Hifla at E7.5 in cardiac precursors, a majority of Hifla $a^{f / 4}$ Nkx2.5$\mathrm{Cre}^{+}$animals survived to E17.5, with only $14 \%$ presenting heart abnormalities. However, another study using a different Nkx2.5Cre line found that most $\mathrm{Hifla}^{f / 4} \mathrm{Nkx} 2.5-\mathrm{Cre}^{+}$mice died between E14.5 and E17.5, and almost all had ventricular abnormalities, including incomplete septation (14). This study also deleted Hifla using other Cre lines, including Myh6-Cre in cardiomyocytes at E12, Wt1-Cre in epicardial cells at E9.5, and Tie2-Cre in endocardial cells at E9.5, and found that these mice all survive to birth. Experiments with conditional deletion of Hiflb in early cardiac lineages are sparse; only one study deleted this gene in adult cardiomyocytes (32). Further research into this factor could be partic-

\section{Table 1. Phenotypes of mice null for HIF pathway genes}

\begin{tabular}{|c|c|c|c|c|}
\hline & Allele & Phenotype & Mouse background & Reference \\
\hline \multirow[t]{2}{*}{ Hifla } & Hifla $a^{\text {tmRsio }}$ & Lethal by E10; heart defects; myocardial thinning & [57BL/6 $\times 129$ & 20 \\
\hline & Hifla $a^{\text {tmipec }}$ & Lethal by E10; cardia bifida & $129 /$ SvJ $\times$ Swiss & 19 \\
\hline & Arnt $t^{t m 10 h a}$ & Lethal between E9.5 and E10.5; placental defects & C57BL/6× 129 & 24 \\
\hline \multirow[t]{4}{*}{ Epas1 (i.e., Hif2a) } & Epast tmiRus & Lethal by E16.5 & {$[57 \mathrm{BL} / 6 \times 129 / \mathrm{Sv}$} & 27 \\
\hline & Epast ${ }^{\text {tmIRus }}$ & Lethal in utero & [57BL/6 (congenic) & 25 \\
\hline & Epast ${ }^{\text {tmIRus }}$ & $1 / 4$ survival; cardiac hypertrophy & [57BL/6 $\times 129$ & 25 \\
\hline & Epast $\}^{\text {tmiFong }}$ & Lethal between E9.5 and E12.5 & $129 / \mathrm{Sv}$ & 26 \\
\hline Hif3a & Hif3a $a^{\text {tmMym }}$ & Viable; abnormal lung development; right ventricle hypertrophy & [57BL/6 & 17 \\
\hline Egln1 (i.e., Phd2) & Eglnt $t^{\text {tmiFong }}$ & Lethal between E12 and E14; placental and heart defects & C57BL/6 $\times 129 / S 6$ & 28 \\
\hline
\end{tabular}




\section{Table 2. Experiments using cardiac conditional knockout of HIF pathway genes}

\begin{tabular}{|c|c|c|c|c|}
\hline & Cre line $^{A}$ & Allele ${ }^{b}$ & Phenotype & Reference \\
\hline \multirow[t]{7}{*}{ Hifla } & $\begin{array}{c}\text { Mesp1-Cre } \\
\text { (E6.5 embryonic mesoderm) }\end{array}$ & Hifla $a^{\text {tm3Rsio/ } / \Delta}$ & $55 \%$ Lethal at E17.5 & 31 \\
\hline & $\begin{array}{c}N k \times 2.5 \text {-Cre } \\
\text { (E7.5 cardiac precursors) }\end{array}$ & Hif1a $a^{\text {tm3Rsio/s }}$ & $\begin{array}{l}\quad \text { } 95 \% \text { Survival to at least E17.5 } \\
\text { Heart abnormalities in } 14 \% \text { of surviving animals }\end{array}$ & 31 \\
\hline & $\begin{array}{c}\text { Nkx2.5-Cre } \\
\text { (E7.5 cardiac precursors) }\end{array}$ & Hifla ${ }^{\text {tm3Rsio/A }}$ & Lethal by E17.5 & 14 \\
\hline & $\begin{array}{c}\text { MLC2v-Cre } \\
\text { (E8.25 ventricles) }\end{array}$ & $H i f 1 a^{t m 3 R s j o / \Delta}$ & Lethal by E12.0 & 13 \\
\hline & $\begin{array}{c}\text { Myh6-Cre } \\
\text { (E12 cardiomyocytes) }\end{array}$ & $H i f 1 a^{t m 3 R s i o / \Delta}$ & Survive to birth & 14 \\
\hline & $\begin{array}{c}\text { Wt1-Cre } \\
\text { (E9.5 epicardial cells) }\end{array}$ & Hiffa $a^{\text {tm3Rsio/s }}$ & Survive to birth & 14 \\
\hline & $\begin{array}{c}\text { Tie2-Cre } \\
\text { (E9.5 endocardial cells) }\end{array}$ & 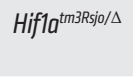 & Survive to birth & 14 \\
\hline Arnt & $\begin{array}{c}\text { Myh6-MerCreMer } \\
\text { (Tam-inducible, cardiomyocytes) }\end{array}$ & $\operatorname{Arnt}^{\text {tm.1.16onz }}$ & Deleted in adults, not tested earlier in development & 32 \\
\hline Vhl & $\begin{array}{c}N k \times 2.5 \text {-Cre } \\
\text { (E7.5 cardiac precursors) }\end{array}$ & $V h t^{t m I l a e}$ & $\begin{array}{l}\text { Lethal by E17.5 } \\
\text { Septal defects, myocardium thinning }\end{array}$ & 15 \\
\hline \multirow[t]{2}{*}{ Egln1 } & $\begin{array}{c}\text { MLCV-Cre } \\
\text { (E8.25 ventricles) }\end{array}$ & Eglntm $1^{\text {tml.18rei }}$ & No reported developmental cardiac phenotypes & 187 \\
\hline & $\begin{array}{c}\text { Myh6-Cre } \\
\text { (E12 cardiomyocytes) }\end{array}$ & Eglnt $1^{\text {tmIKael }}$ & No reported developmental cardiac phenotypes & 75 \\
\hline
\end{tabular}

${ }^{A}$ Embryonic stage of earliest Cre activity and targeted cardiac cell type or tissue are indicated. ${ }^{\mathrm{B}}$ The $\Delta$ indicates a null allele used in combination with a floxed allele to achieve greater knockout efficiency. of the myocardium to meet the proliferating heart's high energy demands (Figure 1B). That both HIF1 $\alpha$ deletion and stabilization in cardiomyocytes could lead to cardiac hypoplasia argues for the complexity of the gene circuitry that HIF1 controls during myocyte proliferation and differentiation. These studies also highlight the requirement for precise timing and appropriate levels of the different HIF isoforms during development. Compensatory roles between the different HIF isoforms, or other factors, may underlie the phenotypes observed in hearts lacking or constitutively stabilizing HIFs. Still, the role for HIFs in launching the cardiac developmental program may be more direct. In frogs, HIF1 $\alpha$ is required for the correct expression of $N k x 2.5$, a master transcription factor important in heart progenitor specification $(35,36)$. A more thorough analysis of the tranularly revealing, since HIF1 $\beta$ dimerizes with all three $\alpha$ isoforms. The discrepancies between these genetic experiments have been attributed to differences in alleles, mouse backgrounds, and the effectiveness and timing of Cre drivers. Taken together, while the range of phenotypes seen in mice deficient in HIF pathway components is heavily influenced by specific experimental parameters, these studies underscore the importance of the HIF pathway in regulating early, rather than late, events of cardiogenesis.

How might the HIF pathway regulate heart development? Recent analyses have argued for roles in regulating fetal cardiomyocyte proliferation and metabolic switching events in specific regions of the heart $(14,15)$. One study reported that HIF1 $\alpha$ promotes cell cycle gene expression by modulating the transcriptional inhibitor p53 in cardiomyocytes (14). Loss of Hifla led to downregulation of the p53 inhibitor macrophage migration inhibitory factor (MIF), upregulation of p53 transcript, and subsequent suppression of $\mathrm{p} 53$ target genes that promote cardiomyocyte proliferation (Figure 1B). This finding could explain the hypoplastic heart phenotype observed in Hifla-null mice; however, the interplay between p53 and HIF is complex, and various reports have argued for both activating and repressive roles of HIF in p53-regulated transcription (33). Interestingly, Mif-null mice are viable and fertile with no reported defects in heart development (34). Another study effectively stabilized HIFs in embryonic cardiomyocytes by deleting $V h l$, which, surprisingly, also led to hypoplasia and embryonic death by E17.5 (15). The authors suggested that degradation of HIFs, specifically HIF1, in appropriate compartments of the heart allows for a switch from glycolytic to oxidative metabolism, which is necessary for appropriate thickening scriptional effects of all HIFs in launching cardiac developmental gene programs, possibly at the single-cell level, is necessary to identify direct and indirect effects of HIF activity.

Numerous cell types contribute to the developing heart, including cardiomyocytes, fibroblasts, endothelial cells, and immune cells (37). The majority of work done so far has focused on HIF in cardiomyocytes, so it will be of interest to understand HIF's role in other cell types that are likely to have distinct hypoxia responses. For example, coronary vasculature development is dependent on HIF, and HIF dysregulation may contribute to clinically important coronary malformations $(38,39)$. Recent evidence has also shown HIF1's involvement in sympathetic innervation of the heart (40). The transcriptional response to hypoxia likely integrates multiple factors independent of HIF, including chromatin factors that can sense oxygen and could be major effectors of transcriptional events found in the hypoxic embryonic heart $(41,42)$. Also, the relationship between HIF and noncoding RNAs is likely to be an additional axis influencing heart development $(43,44)$.

\section{HIF's role in congenital heart disease}

Congenital heart disease (CHD) is the most common birth defect, occurring in 1 in 100 live births $(45,46)$. Approximately $10 \%$ of CHD arises from de novo autosomal dominant or inherited autosomal recessive mutations, and many genetic translocations, copy number variations, and point mutations have been identified over the past 20 years $(47,48)$. The remaining $\mathrm{CHD}$ cases are thought to arise from a combination of both genetic and environmental factors (49). Given the importance of the HIF axis in heart development, oxygen levels in utero and polymorphisms in HIF pathway 
genes can contribute to CHD. Insights into this may lie in genetic population studies of groups that live at high altitudes, exposed to chronic hypoxia. Remarkably, CHD prevalence has been reported to be ten times higher in these groups than in groups living at sea level (50). Certain genetic polymorphisms, such as those found in Hif $2 a$, that have allowed adaptation to high altitude have also been implicated in contributing to abnormal heart development $(26,51)$. Efforts to model in utero hypoxia have revealed important insights into the potential contributors and events leading to CHD. In one study, exposure to hypoxia in mouse embryos lacking a single copy of either of the essential cardiac development genes $T b x 1$ and $N k x 2.5$ led to an increase in heart malformations and embryonic death (52). This genetic sensitization, combined with abnormal oxygen levels, highlights the combinatorial effects of genetics and environment on heart development. The epigenetic mechanisms linking in utero hypoxia to cardiovascular disease later in life, and possibly across generations, are a current research focus, although the roles that HIFs play are not yet clear (reviewed in ref. 53).

\section{HIF and cardiac regeneration}

Mature mammalian cardiomyocytes have very low proliferative capacity and are not replenished in damaged adult hearts to any substantial degree. Repopulating damaged areas of the heart with functional cardiomyocytes is a long-sought goal of regenerative medicine and may benefit from refinement of induced pluripotent stem cell techniques. Links between cellular stemness, hypoxia, and HIF activity have been established (54). Many adult stem cells reside in hypoxic niches, an environment that is thought to keep cells in an undifferentiated state, limiting oxidative DNA damage and promoting glycolysis as a main energy source (55). Additionally, genes encoding pluripotency factors (e.g., Oct4) are direct targets of the HIF pathway, specifically HIF $2 \alpha$, supporting the hypothesis that the HIF axis is a direct regulator of pluripotency. However, recent experiments have cast doubt on the presence of resident stem cells in the mammalian heart (56). Instead, a tiny population of adult cardiomyocytes may retain the ability to reenter the cell cycle under extreme circumstances, such as hypoxia (57).

Fate mapping has suggested a limited number of proliferative adult cardiomyocytes (58). The role of hypoxia and HIFs in this process is now being explored. In one study, adult hypoxic cardiomyocytes were identified by fusing of HIF1 $\alpha$ 's oxygen-dependent degradation domain to a tamoxifen-inducible CreERT2 recombinase (57). Introducing this transgene into mice harboring a floxed-TdTomato reporter turns cells red $\left(\mathrm{TdT}^{+}\right)$if they are hypoxic at the time of tamoxifen treatment. In 1-month old mice, a small percentage of cardiomyocytes were hypoxic by this assay. Remarkably, the number of $\mathrm{TdT}^{+}$cardiomyocytes, albeit small, increased over time without additional tamoxifen treatment, suggesting that a tiny number of cardiomyocytes $(0.01 \%-0.06 \%$ of cells) in the adult can reenter the cell cycle. Molecular characterization of these rare cardiomyocytes may reveal what makes these cells special, with hopes to instill these features into nondividing cardiomyocytes.

In contrast to mammals, zebrafish and amphibians efficiently repair damaged hearts through a process of dedifferentiation and proliferation of existing cardiomyocytes (59). Ventricular amputation of zebrafish hearts induces localized hypoxia at the resection site that promotes cardiomyocyte dedifferentiation and prolifera- tion (60). Expression of a dominant-negative form of HIF1 $\alpha$ in these hearts or exposure to hyperoxia prevented this regeneration. Interestingly, in the more regenerative fish heart, HIF-mediated vascular growth contributes to cardiomyocyte repopulation by serving as a cellular scaffold (61). The neonatal mouse heart is able to regenerate for a few days after birth, and exposing adult mice to hypoxia may also promote cardiac regeneration $(62,63)$. Recently, moderate hypoxia was shown to affect human cardiomyocyte proliferation through upregulation of YAP1 (64). Current clinical trials are exploring whether hypoxia can ameliorate cardiac damage in humans (65, 66). At this time, the mechanisms underlying cardiomyocyte cell cycle reentry under hypoxic conditions are not fully understood, and the role HIFs play in this process remains undefined.

\section{HIF and cardiac metabolism}

HIF plays a crucial role in shaping the metabolic response in the heart (Figure 2). The heart synthesizes and consumes approximately $6 \mathrm{~kg}$ of ATP every day, largely for contraction and ion flux $(67,68)$. Cellular metabolism is inextricably linked with cardiac contractility. In the healthy human heart, oxidative phosphorylation generates almost all of the ATP ( 95\%), with fatty acids utilized as substrate ( 70\%) (67). Glucose and other carbohydrates provide most of the remainder, with minor contributions from other pathways (67). However, given the crucial, unremitting need for proper cardiac function, the heart is omnivorous and will consume any substrate available to sustain contractility, as seen in the increased reliance on glucose in aging and failing hearts (67). Glycolysis is also increased in other cardiac diseases, and in diabetes there is increased consumption of ketone bodies $(67,69,70)$.

While HIF1 promotes glycolysis during hypoxia, it also influences metabolism under normoxic conditions. Deleting HIF1 $\alpha$ in cardiomyocytes alone causes decreased ATP, lactate, and phosphocreatine levels, in addition to impaired cardiac contractility (71). Paradoxically, overexpressing myocardial HIF1 $\alpha$ can also produce contractile dysfunction, despite increased ATP, glucose metabolism, glycogen stores, and lactate production (72-74). Similarly, cardiac loss of PHD or VHL function, which stabilizes HIF1 $\alpha$ (and HIF $2 \alpha$ ), also leads to upregulation of glycolytic genes and concomitant loss of contractility (75-77). These results suggest that tight control of HIF1 $\alpha$ expression is crucial to proper cardiac function and that HIF1 $\alpha$ 's effects on metabolism extend beyond glycolysis.

HIF1 $\alpha$ also influences mitochondrial metabolism. Reduced HIF activity leads to mitochondrial loss and lipid accumulation, along with decreased oxidative phosphorylation and fatty acid metabolism $(72,73,76,77)$. Reactive oxygen species (ROS) are also generated during hypoxia from disruption of the electron transport chain and a perturbed redox state (78). Detailed work has demonstrated that HIF1 $\alpha$ mitigates this toxicity by limiting TCA activity and decreasing mitochondrial mass through upregulation of the mitochondrial proteins PDK1 and BNIP3 (78-81).

HIF1 expression and activation can also be regulated by metabolite feedback loops. For example, increased glucose (or GLUT1 expression) limits HIF1 $\alpha$ expression through upregulation of ubiquitin degradation pathways (82). Also, in addition to its role in the TCA cycle, succinate is generated as a byproduct of an $\alpha$-ketoglutarate-dependent PHD hydroxylation reaction and can act as a rheostat to modulate PHD activity and HIF stability (83-86). 


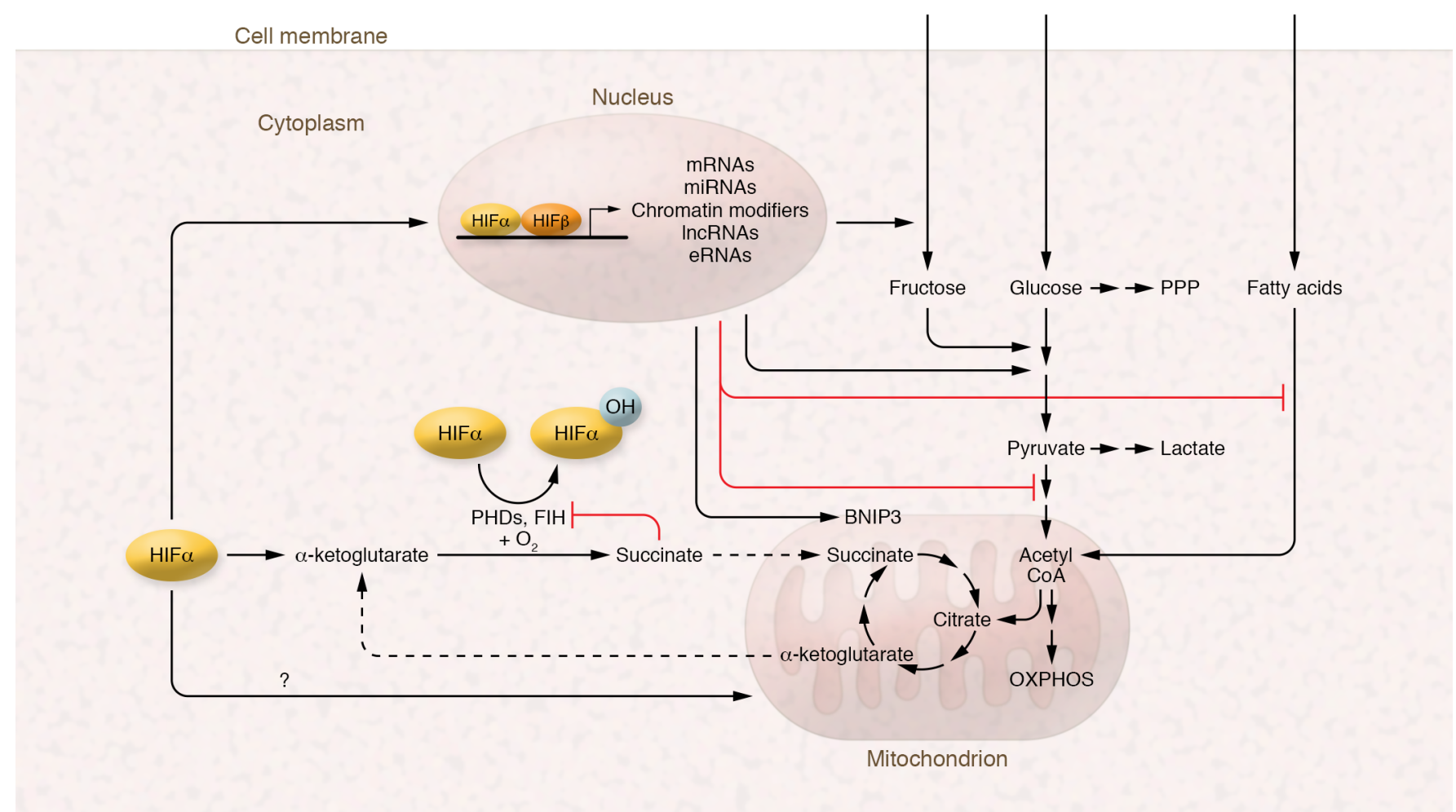

Figure 2. Effects of HIF on metabolism. HIF expression or stabilization has many effects on cell metabolism, both directly and indirectly. Under normoxic conditions, HIF1 $\alpha$ and HIF2 $\alpha(\mathrm{HIF} \alpha$ ) are hydroxylated by PHDs (and FIH) using available oxygen and $\alpha$-ketoglutarate, which leads to proteosomal degradation. When oxygen tension is low, HIF $\alpha$ translocates to the nucleus, where it binds to DNA with its heterodimeric binding partner HIF $\beta$ to initiate transcription of HIF target genes. These transcription products affect all levels of cellular metabolism to reduce oxidative phosphorylation (OXPHOS) in mitochondria and favor glycolysis, from substrate transport to apoptotic signaling molecules (e.g., BNIP3). Some evidence suggests that HIF $\alpha$ may also directly modulate mitochondrial metabolism, through a currently undefined mechanism. Metabolite levels are independently affected by changes in oxygen tension and HIF expression through reduction of PHD activity, which influences concentrations of several citric acid metabolites (e.g., $\alpha$-ketoglutarate and succinate). Dashed lines indicate transport across the mitochondrial membrane, where these metabolites serve distinct roles in each location. PPP, pentose phosphate pathway.

Work in cancer cells shows that several additional citric acid and glycolytic metabolites can also regulate PHD activity and HIF stability $(84,85,87)$, but additional mechanistic studies will be needed to assess their importance in the heart.

While HIF1 drives the initial response to hypoxia, HIF2 appears to regulate the long-term response to restore oxygen homeostasis. Global loss of HIF $2 \alpha$ leads to cardiac hypertrophy, along with impaired mitochondrial metabolism and increased ROS generation due to loss of antioxidant enzymes (25). Cardiomyocyte-specific loss of HIF $2 \alpha$ increases ischemic damage (88). HIF $2 \alpha$ overexpression in cardiomyocytes also increases transcription of HIF target genes (and produces a dilated cardiomyopathy) (75), indicating a role for HIF2 in chronic hypoxia and mitochondrial maintenance. Additionally, VHL deletion in adipocytes causes cardiac hypertrophy via HIF2-dependent changes in lipid metabolism and inflammatory signaling (89). Interestingly, global loss of FIH, the other HIF hydroxylase, leads to an increased metabolic rate and insulin sensitivity that does not coincide with increases in glycolysis, fatty acid oxidation, or HIF1 target gene expression (90, 91). Rather, FIH appears to regulate mitochondrial ROS production and glycogen storage (91). Limited data exist on HIF3 in the heart, but recent work in cardiomyocytes in vitro indicates it may behave similarly to PHDs by limiting expression of typical HIF1 targets including Glut1, Epo, and Glut4 (92). HIF3 expression was also found to be upregulated in response to insulin (93). Additional studies have demonstrated that DMOG, desferrioxamine, PHD inhibitors, and other small molecules can also modulate HIF-dependent metabolic processes $(83,94,95)$. While HIF1 appears to be the major regulator of cellular metabolism, further study will be necessary to specifically delineate the roles of each of the HIF proteins and regulators in cardiovascular metabolism.

Unsurprisingly, HIF signaling affects the metabolic response to heart disease in myriad ways. Many cardiac pathologies lead to reduced oxygen availability either directly (reduced oxygen delivery) or indirectly (mismatch between demand and supply). Both HIF1 and HIF2 are expressed after acute ischemic injury, and HIF1 has been shown to be protective, at least partly as a result of increased glycolysis and reduced oxidative metabolism $(74,96-$ 100). Chronic ischemia can develop from atherosclerosis, aortic stenosis, hypertrophic cardiomyopathy, and hypertension, all of which can lead to heart failure. Although often described as "nonischemic cardiomyopathy," hypertrophy and dilation can also produce stabilization of HIF1 and upregulation of its metabolic pathways $(73,101)$. Given the reduced ATP production of glycolysis compared with oxidative phosphorylation, long-term HIF1 stabilization may not always be beneficial, as observed in heart failure 
patients whose hearts utilize glycolysis to a greater degree than those of healthy counterparts $(67,69,73,101)$. Recent work also indicates that HIF-dependent maladaptive pathways, e.g., fructolysis, can be upregulated under cardiac stress and contribute to cardiac pathology (101). Diabetes, obesity, and insulin resistance can also modify HIF's metabolic effects through reduced HIF1 expression and glucose uptake as well as increased oxidative stress (86, 102-105). Given the increasing prevalence of diabetes and metabolic disorders, additional study of the effects of metabolic stress on HIF signaling in the heart is needed to develop more effective therapies for these diseases.

\section{HIF and angiogenesis}

Following the path-breaking work of Judah Folkman (106), the understanding of angiogenesis has burgeoned over the past 30 years. This work initially focused on VEGF and a few other molecules for positive angiogenic treatments, and their antagonists for cancer therapies and age-related macular degeneration. Exciting work has also been done on angiogenesis in noncardiac vascular beds, especially the retina and peripheral extremities; these models form the basis of much of our understanding of clinical angiogenesis and have been well reviewed elsewhere (107-111).

Genetic evidence suggests that modulation of HIF activity in the cardiovascular system could have clinical benefit. Several SNPs at the Hifla locus are associated with vascular response (112-115). As it became clear that HIF was a principal regulator of angiogenesis, mediating VEGF expression and a host of other molecules, clinical efforts focused on increasing HIF1 expression in peripheral artery disease to induce collateral circulation in the lower extremities. While preclinical and phase I studies produced encouraging results, a larger clinical trial ultimately found no significant functional improvement (109, 112, 116-118). Preclinical work also indicated that viral expression of HIF1 could improve cardiac perfusion after ischemia (119); however, subsequent clinical studies were less encouraging $(120,121)$.

Although much focus has been on HIF1, HIF2 also plays an important, distinctive role in angiogenesis. Like HIF1, several HIF2 (Epas1) knockout models displayed vascular defects, although the specific phenotypes differed between genetic backgrounds and from those seen in HIF1 deletion (122). While HIF1 and HIF2 share a number of transcriptional targets to activate angiogenesis, the limited and cell-specific nature of HIF2 expression (brain, heart, lungs, liver, kidneys, intestines, vasculature) suggests it serves a nonredundant role in this process (123). Studies to date indicate that HIF1 is crucial to early steps (sprouting, intussusception), while HIF2 influences later stages of vessel stabilization and maturation $(122,124)$. Additionally, HIF1 and HIF2 have been reported to have different sensitivities to oxygen tension (with higher HIF1 hydroxylation and turnover at physiological levels of hypoxia) and different temporal expression in the hypoxic endothelium (HIF1 > HIF2 in the first 24 hours, HIF2 > HIF1 after 24 hours), which appears to support their complementary roles in vessel formation and development $(124,125)$. Limited data on HIF3 suggest it can also modulate angiogenesis, with delayed expression in the endothelium upon hypoxia exposure (similar to HIF2) and some effects on heart, lung, and vascular development (125). While therapeutic modulation of HIF2 in clinical trials has largely been limited to small-molecule inhibitors to limit tumor vascular formation, preclinical study of HIF2 stabilization indicates that it may improve perfusion in ischemic injury $(122,126)$. For now, more definitive evaluation of HIF modulation for cardiac angiogenesis awaits more specific therapeutics and delivery methods, improved noninvasive evaluation of perfusion, and a deeper understanding of the underlying molecular signaling.

\section{HIF and preconditioning}

The concept of preconditioning tissue with short intervals of ischemia to limit more severe ischemic injury has been a tantalizingly attractive clinical strategy for decades. Naturally occurring responses to ischemia in the heart suggest the benefits of this approach. Patients with myocardial infarction who had preceding angina or collateral vessels had better recovery than those who did not $(112,127,128)$, suggesting that prior exposure to hypoxia and angiogenesis, or perhaps "remodeling" of metabolism, both of which are likely to be HIF-related, may be protective. A number of recent reviews discuss HIF and preconditioning in the heart (10, 112, 129-131). Treatment, whether it is ischemia, hypoxia, or small molecules that activate related pathways, can be delivered either directly to the tissue of interest, or indirectly (often referred to as remote preconditioning). The timing of treatment can also vary, including before (preconditioning), during, or after prolonged ischemic insult (postconditioning). Here we highlight a few recent publications that provide new insight into mechanisms underlying the protective effects of preconditioning.

Both genetic and pharmacological studies suggest that HIF is involved in preconditioning. Many of these protective effects relate to transcriptional activity in known pathways that promote glycolysis and oxygen delivery, or minimize oxidative metabolism, which all fall into the late phase of preconditioning ( $>24$ hours after treatment) $(10,112,130)$. However, some evidence suggests that HIF1 is also involved in the early phase of preconditioning (within hours of therapy) before transcription is upregulated, possibly by directly modulating mitochondrial metabolism $(78,132)$. The advantages of HIF signaling are not limited to cardiomyocytes, as deletion of HIF1 in endothelial cells also abolishes cardioprotection conferred by ischemic preconditioning $(112,133)$. Interestingly, while HIF is involved in several of these pathways, its activation may not be necessary for some aspects of protection, as regulation of downstream molecules such as adenosine is also beneficial $(112,129-131,134)$. These results suggest that in addition to HIF itself, identification of HIF targets involved in preconditioning may produce additional candidates to more specifically modulate cardioprotective pathways.

In addition to direct preconditioning, there has been exciting recent progress in understanding remote preconditioning to protect the heart. These models usually involve temporary ischemia of a remote region prior to cardiac injury, typically a limb, but systemic treatments to alter oxygen availability can also be considered forms of remote conditioning. Numerous studies have found that exposure to ambient hypoxia, administration of hypoxic blood, or small-molecule inhibitors of HIF degradation can confer cardiac protection before ischemic injury $(10,63,100,112$, $129,135,136)$. While remote preconditioning can provide protection through both humoral and neural pathways, humoral factors 


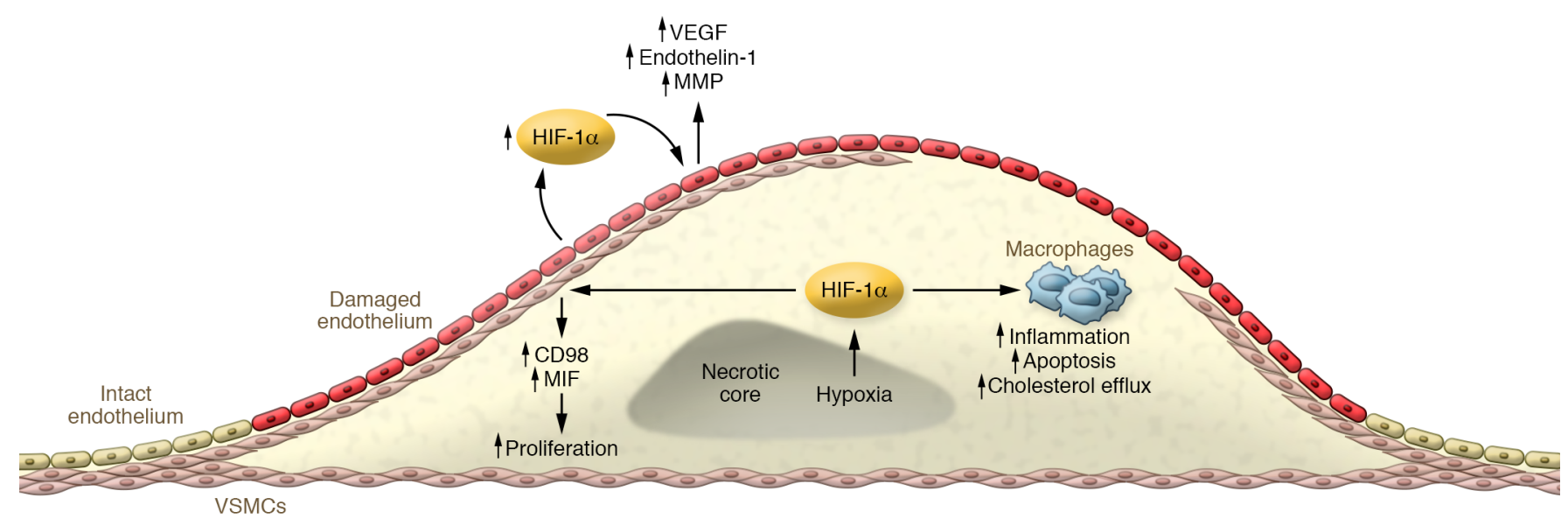

Figure 3. HIF1 $\alpha$ plays multiple roles in the development of atherosclerosis. This sketch shows the major effects of HIF1 $\alpha$ on the three most important cell types in atherosclerosis: endothelial cells, macrophages, and smooth muscle cells. Whereas HIF1 $\alpha$ directly induces vascular endothelial growth factor (VEGF), endothelin-1, and matrix metalloproteinases (MMPs) in endothelial cells to facilitate angiogenesis, its effect on vascular smooth muscle cells is to induce proliferation of these cells in the atheroma by upregulating factors such as CD98 and macrophage migration inhibitory factor (MIF). HIF1 $\alpha$ also regulates lesional macrophage foam cell function by rendering the cells more inflammatory and apoptotic while suppressing their capacity to metabolize lipids.

including erythropoietin, adenosine, and NO are at least partially HIF dependent $(78,129,131)$, suggesting that HIF is also involved in remote preconditioning.

While much preclinical work has focused on preconditioning, this may not be a realistic option for most at-risk patients. Postconditioning could provide clinical benefit, especially if it could be applied at the time of coronary intervention. Studies have suggested that ischemic postconditioning can limit ischemic damage in the heart, but others indicate this treatment may not offer long-term benefits $(129,131,137,138)$. Pharmacological modulation through PHD inhibitors and/or HIF antagonists could allow more precise targeting and temporal regulation of HIF signaling to enhance its protective effects in future studies of postconditioning.

Since the first demonstration of ischemic preconditioning of the heart (139), substantial effort has gone into elucidating the mechanisms of this protection for clinical application. Unfortunately, inconsistency in the timing and delivery of preconditioning therapies in both preclinical and clinical studies makes it difficult to compare results and discern the ideal window for treatment $(137,140)$. These issues, combined with difficulties inherent in excluding confounding factors such as age, comorbidities, and patient presentation, limit the conclusions that can be drawn from work thus far (137, 140). Meaningful progress on new HIF-based therapies will only be possible when better preclinical models are combined with carefully controlled clinical trials and relevant endpoints.

\section{The role of HIF in atherosclerosis}

Atherosclerosis of the coronary arteries, with subsequent thrombotic occlusion, is the principal cause of myocardial infarction. Among the numerous factors contributing to atherosclerosis, the two most important are dyslipidemia and inflammation. It is generally accepted that the macrophage is the most important inflammatory cell in the etiology of atherosclerosis owing to its ability take up and process lipids and its contribution to inflammation in the plaque. Vascular smooth muscle cells (VSMCs) also play an important role, as their proliferation and migration toward the neointima form the fibrous cap that protects the inflammatory contents of the plaque from contacting the blood and initiating a thrombus. Endothelial cells (ECs) overlying the artery play a key role in regulating the influx of lipoprotein particles and inflammatory cells into the intimal space where atherosclerosis occurs.

Hypoxia plays an important role in atherogenesis (141). Over years, buildup of extracellular matrix and lipid material leads to formation of hypoxic areas in the plaque. This is especially true of macrophage-rich areas (142), and VSMCs and ECs also both respond to hypoxia by expressing HIF. Whereas direct evidence of HIF $1 \alpha$ expression is seen in both carotid and femoral endarterectomy from patients (143), strongly indicating its participation in atherogenesis, little is known about HIF2 $\alpha$ 's role. Many HIF1-regulated genes are expressed in the plaque region, including VEGF and endothelin-1 (144). While HIF1 influences macrophage functions known to mediate atherogenesis, it also regulates other innate immune cells such as neutrophils (145-147) and dendritic cells (148-150) as well as adaptive T and B cells (151-156), in which HIF1 $\alpha$ controls cellular functions such as survival, migration, and cytokine production. Although the effects of HIF expression can be wide-ranging, its effects in the three most important cell types of atherosclerosis - macrophages, VSMCs, and ECs - are of particular interest (Figure 3).

Macrophages. Macrophages contribute to atherogenesis through multiple pathways, and hypoxia affects many of these $(157,158)$. Atherosclerotic plaque is hypoxic. Under these hypoxic conditions, lipid accumulation is increased, the ability of macrophages to efflux cholesterol is compromised, and HIF1 $\alpha$ also directly suppresses the expression of $\mathrm{ABCA1}$, an important transport protein that facilitates the excretion of cholesterol out of lipid-loaded macrophages (159-161). Interestingly, ApoA1, the key apolipoprotein that acts as a cholesterol acceptor in reverse cholesterol transport, was recently found to be expressed by macrophages, and its expression is also inhibited by HIF1 $\alpha$ (160). Studies using HIF1 $\alpha$-deficient myeloid cells have revealed that HIF1 $\alpha$ has a pleiotropic role in macrophage function, including its ability to regulate glucose metabolism, 
chemotaxis, and apoptosis (162). It is possible that the increase in apoptosis is due to accumulation of unesterified cholesterol in macrophages under hypoxic conditions (163). In vivo studies with LDL receptor-null mice transplanted with bone marrow isolated from HIF $1 \alpha$-null mice showed that HIF1 $\alpha$ deficiency in myeloid cells led to a $72 \%$ reduction in atherosclerosis in these mice (162).

HIF1 $\alpha$ is intimately involved in the inflammatory response of macrophages. Activating macrophages with agents such as LPS or IFN- $\gamma$ prompts these cells to become proinflammatory through HIF1 $\alpha$ activation, eventually leading to production of cytokines like TNF- $\alpha$ and IL- 6 as well as inducible NO synthase (iNOS) (164). This is due, in part, to the activation of macrophages leading to the accumulation of succinate, which acts to stabilize HIF1 $\alpha$ and boost the transcription of proinflammatory genes (165). Moreover, deficiency of HIF1 $\alpha$ in macrophages leads the cells to adopt an antiinflammatory M2 polarization phenotype (166). HIF2 $\alpha$ also appears to regulate M2 polarization in macrophages (167). Whereas LPS or IFN- $\gamma$ increases the production of HIF1 $\alpha$, they strongly suppress HIF2 $\alpha$ expression. On the other hand, M2-inducing agents such as IL- 4 and IL-13 enhance the production of HIF $2 \alpha$.

Vascular smooth muscle cells. A key feature of atherosclerosis is the migration and proliferation of VSMCs. Once in the neointima, VSMCs secrete collagen and other structural materials that form the plaque's fibrous cap. Hypoxia and HIF1 $\alpha$ play an important role in VSMC proliferation (168), but the timing of this proliferation has not been determined. It is also not clear exactly what triggers the migration of these cells, although hypoxia is a leading candidate (169). Growth factors such as PDGF and FGF may trigger VSMC mobility (170); whether or not these factors play a role in vivo and the extent to which they are regulated by hypoxia have not been conclusively determined. A recent study has identified CD98 as a potential inducer of VSMC proliferation during intermediate stages of atherosclerosis (171). It is interesting that the heavy chain of CD98, also known as SLC3A2, is a target of HIF1 $\alpha$. Intermittent hypoxia was also found to augment the VSMC proliferation by upregulating inflammatory factors such as IL-6 and epiregulin (172).

MIF is another important cytokine in VSMCs that responds to hypoxia. Stabilization of HIF1 $\alpha$ leads to increased MIF production, whereas deletion of HIF1 $\alpha$ in SMCs leads to reduced MIF production (173). The increase in proliferation seen in SMCs cultured under hypoxic conditions is abrogated when the cells are treated with MIF siRNA (173). HIF1 $\alpha$ can also contribute to the calcification of atherosclerotic plaques by mediating the osteochondrogenic differentiation of VSMCs (174).

Endothelial cells. ECs do not normally encounter hypoxia, as they are bathed in a constant flow of blood. Thus, it appears that HIF1 $\alpha$ expression in ECs is triggered by other factors such as lipids, cytokines, or reactive oxidative products that may be induced during inflammation. HIF1 $\alpha$ expressed by ECs can promote monocyte chemotaxis to the atherosclerosis-prone vessel wall and thereby contribute to the growth of atherosclerotic plaque (175). In hypoxia, when blood flow is interrupted or oxygen-carrying capacity of the blood is diminished, stabilized HIF1 $\alpha$ has substantial functional effects in the endothelium. In addition to VEGF, HIF1 $\alpha$ upregulates the VEGF receptors VEGFR1 and VEGFR2 on ECs. Atherosclerosis-related changes in endothelial permeability and EC proliferation are affected by VEGF interacting with its receptors (176).
Angiogenesis is a key feature of atherosclerosis. HIF1 $\alpha$ mediates the expression of several genes, including endothelin-1 (177), matrix metalloproteinase (178), and VEGF (179), that facilitate angiogenesis in the plaque. Interestingly, while oxidized LDL can promote angiogenesis by inducing HIF1 $\alpha$ expression in macrophages (180), native LDL has an antiangiogenic effect by inhibiting HIF expression in ECs (181). One of the most important functions of EC is the production of $\mathrm{NO}$ as a powerful vasodilator. HIF1 $\alpha$ upregulates iNOS as well as cytochrome $c$ oxidase to increase NO production. This relaxes VSMCs and dilates the blood vessel, increasing oxygen supply to the tissue (182).

There is little doubt that HIF1 $\alpha$ is a major player in the pathogenesis of atherosclerosis. However, whether HIF1 $\alpha$ acts to exacerbate or inhibit atherosclerosis likely depends on the cell type in which it is expressed as well as the timing of its expression during the course of the disease. A key requirement in considering HIF1 $\alpha$ as a therapeutic target for atherosclerosis would be specificity both in the delivery of HIF regulators to the plaque and in targeting of specific cells within the plaque. A greater understanding of the timing and cellular distribution of HIF1 $\alpha$ in the plaque is needed to fulfill the promise of modulating the HIF axis in atherosclerosis.

\section{Summary}

We have reviewed only a portion of the recent work on the HIF axis in the heart. There are exciting new developments in each highlighted area that point to how little we know and how much there is to discover. This includes the potential antagonism of HIF1 and HIF2 and their effects on angiogenesis, fibrosis, and cardiac metabolism (183). Currently, several small molecules that modulate HIF signaling are being assessed in clinical trials (94). One of these compounds, the PHD inhibitor roxadustat, is currently under review in the United States and has already been approved in several countries for anemia associated with chronic kidney disease (184). Other agents that inhibit the action of HIF2 may be useful in pulmonary hypertension and polycythemia (185), and are in clinical trial for treatment of renal cell carcinoma (186). As these enter the clinic, it will be important to determine what effects these treatments may have on patients with heart disease. Perhaps as methods for tissue-specific gene expression and modulation advance, manipulation of HIF activity will become an attractive target in the heart itself. It is easy to imagine a role for such therapies in focused angiogenesis or metabolic modification. The HIF axis is a fertile area of investigation and, increasingly, is a ripe target for clinical manipulation. It will be important to balance the protective and maladaptive effects of HIF signaling to preserve, and improve, cardiac function.

\section{Acknowledgments}

AKK is supported by a Ruth Kirschstein Postdoctoral Fellowship (F32-HL149319) and a Burroughs Wellcome Fund Postdoctoral Enrichment Program Award. AKK and ALW have been supported by NIH grant T32-HL115505.

Address correspondence to: Ralph V. Shohet, Department of Medicine, John A. Burns School of Medicine, University of Hawaii, BSB 304, 651 Ilalo Street, Honolulu, Hawaii 96713, USA. Phone: 808.692.1469; Email: shohet@hawaii.edu. 
1. Wang GL, Semenza GL. Purification and characterization of hypoxia-inducible factor 1. J Biol Chem. 1995;270(3):1230-1237.

2. Ivan M, et al. HIFalpha targeted for VHL-mediated destruction by proline hydroxylation: implications for $\mathrm{O} 2$ sensing. Science. 2001;292(5516):464-468.

3. Jaakkola P, et al. Targeting of HIF-alpha to the von Hippel-Lindau ubiquitylation complex by O2-regulated prolyl hydroxylation. Science. 2001;292(5516):468-472.

4. Majmundar AJ, et al. Hypoxia-inducible factors and the response to hypoxic stress. Mol Cell. 2010;40(2):294-309.

5. Duan C. Hypoxia-inducible factor 3 biology: complexities and emerging themes. Am J Physiol Cell Physiol. 2016;310(4):C260-C269.

6. Spater D, et al. How to make a cardiomyocyte. Development. 2014;141(23):4418-4431.

7. Noseda M, et al. Cardiopoietic factors: extracellular signals for cardiac lineage commitment. Circ Res. 2011;108(1):129-152.

8. Bruneau BG. Signaling and transcriptional networks in heart development and regeneration. Cold Spring Harb Perspect Biol. 2013;5(3):a008292.

9. Dunwoodie SL. The role of hypoxia in development of the Mammalian embryo. Dev Cell. 2009;17(6):755-773.

10. Bishop T, Ratcliffe PJ. HIF hydroxylase pathways in cardiovascular physiology and medicine. Circ Res. 2015;117(1):65-79.

11. Patterson AJ, Zhang L. Hypoxia and fetal heart development. Curr Mol Med.2010;10(7):653-666.

12. Lee YM, et al. Determination of hypoxic region by hypoxia marker in developing mouse embryos in vivo: a possible signal for vessel development. Dev Dyn. 2001;220(2):175-186.

13. Krishnan J, et al. Essential role of developmentally activated hypoxia-inducible factor 1alpha for cardiac morphogenesis and function. Circ Res. 2008;103(10):1139-1146.

14. Guimaraes-Camboa N, et al. HIF1 $\alpha$ represses cell stress pathways to allow proliferation of hypoxic fetal cardiomyocytes. Dev Cell. 2015;33(5):507-521.

15. Menendez-Montes I, et al. Myocardial VHLHIF signaling controls an embryonic metabolic switch essential for cardiac maturation. Dev Cell. 2016;39(6):724-739.

16. Jain S, et al. Expression of ARNT, ARNT2, HIF1 alpha, HIF2 alpha and Ah receptor mRNAs in the developing mouse. Mech Dev. 1998;73(1):117-123.

17. Yamashita T, et al. Abnormal heart development and lung remodeling in mice lacking the hypoxia-inducible factor-related basic helixloop-helix PAS protein NEPAS. Mol Cell Biol. 2008;28(4):1285-1297.

18. Kenchegowda D, et al. Vulnerability of the developing heart to oxygen deprivation as a cause of congenital heart defects. JAm Heart Assoc. 2014;3(3):e000841.

19. Compernolle V, et al. Cardia bifida, defective heart development and abnormal neural crest migration in embryos lacking hypoxia-inducible factor-1alpha. Cardiovasc Res. 2003;60(3):569-579.

20. Ryan HE, et al. HIF-1 alpha is required for solid tumor formation and embryonic vascularization. EMBO J.1998;17(11):3005-3015.
21. Kotch LE, et al. Defective vascularization of HIF1alpha-null embryos is not associated with VEGF deficiency but with mesenchymal cell death. Dev Biol. 1999;209(2):254-267.

22. Iyer NV, et al. Cellular and developmental control of $\mathrm{O} 2$ homeostasis by hypoxia-inducible factor 1 alpha. Genes Dev. 1998;12(2):149-162.

23. Maltepe E, et al. Abnormal angiogenesis and responses to glucose and oxygen deprivation in mice lacking the protein ARNT. Nature. 1997;386(6623):403-407.

24. Kozak KR, et al. ARNT-deficient mice and placental differentiation. Dev Biol.1997;191(2):297-305.

25. Scortegagna $M$, et al. Multiple organ pathology, metabolic abnormalities and impaired homeostasis of reactive oxygen species in Epas1 $1 /$ mice. Nat Genet. 2003;35(4):331-340.

26. Peng J, et al. The transcription factor EPAS-1/ hypoxia-inducible factor 2alpha plays an important role in vascular remodeling. Proc Natl Acad Sci U S A. 2000;97(15):8386-8391.

27. Tian $\mathrm{H}$, et al. The hypoxia-responsive transcription factor EPAS1 is essential for catecholamine homeostasis and protection against heart failure during embryonic development. Genes Dev . 1998;12(21):3320-3324.

28. Takeda K, et al. Placental but not heart defects are associated with elevated hypoxia-inducible factor alpha levels in mice lacking prolyl hydroxylase domain protein 2. Mol Cell Biol. 2006;26(22):8336-8346.

29. Bamforth SD, et al. Cardiac malformations, adrenal agenesis, neural crest defects and exencephaly in mice lacking Cited2, a new Tfap2 co-activator. Nat Genet. 2001;29(4):469-474.

30. Yin Z, et al. The essential role of Cited2, a negative regulator for HIF-1alpha, in heart development and neurulation. Proc Natl Acad Sci U S A. 2002;99(16):10488-10493.

31. O'Reilly VC, et al. Gene-environment interaction demonstrates the vulnerability of the embryonic heart. Dev Biol. 2014;391(1):99-110.

32. Wu R, et al. Cardiac-specific ablation of ARNT leads to lipotoxicity and cardiomyopathy. JClin Invest. 2014;124(11):4795-4806.

33. Sermeus A, Michiels C. Reciprocal influence of the p53 and the hypoxic pathways. Cell Death Dis. 2011;2:e164.

34. Bozza M, et al. Targeted disruption of migration inhibitory factor gene reveals its critical role in sepsis. J Exp Med.1999;189(2):341-346.

35. Nagao K, et al. HIF-1alpha signaling upstream of NKX2.5 is required for cardiac development in Xenopus. JBiol Chem. 2008;283(17):11841-11849.

36. Prall OW, et al. An Nkx2-5/Bmp2/Smad1 negative feedback loop controls heart progenitor specification and proliferation. Cell. 2007;128(5):947-959.

37. Pinto AR, et al. Revisiting cardiac cellular composition. Circ Res. 2016;118(3):400-409.

38. Tao J, et al. Epicardial HIF signaling regulates vascular precursor cell invasion into the myocardium. Dev Biol. 2013;376(2):136-149.

39. Wikenheiser J, et al. Altered hypoxia-inducible factor-1 alpha expression levels correlate with coronary vessel anomalies. Dev Dyn. 2009;238(10):2688-2700.

40. Bohuslavova R, et al. HIF-1 $\alpha$ is required for devel- opment of the sympathetic nervous system. Proc Natl Acad Sci U S A. 2019;116(27):13414-13423.

41. Batie M, et al. Hypoxia induces rapid changes to histone methylation and reprograms chromatin. Science. 2019;363(6432):1222-1226.

42. Chakraborty AA, et al. Histone demethylase KDM6A directly senses oxygen to control chromatin and cell fate. Science. 2019;363(6432):1217-1222.

43. Peng $X$, et al. The interplay between HIF-1alpha and noncoding RNAs in cancer. J Exp Clin Cancer Res. 2020;39(1):27.

44. Gomes CPC, et al. Regulatory RNAs in heart failure. Circulation. 2020;141(4):313-328.

45. van der Linde D, et al. Birth prevalence of congenital heart disease worldwide: a systematic review and meta-analysis. J Am Coll Cardiol. 2011;58(21):2241-2247.

46. Liu Y, et al. Global birth prevalence of congenital heart defects 1970-2017: updated systematic review and meta-analysis of 260 studies. Int $J$ Epidemiol. 2019;48(2):455-463.

47. Cowan JR, Ware SM. Genetics and genetic testing in congenital heart disease. Clin Perinatol. 2015;42(2):373-393.

48. Pierpont ME, et al. Genetic basis for congenital heart disease: revisited: a scientific statement from the American Heart Association. Circulation. 2018;138(21):e653-e711.

49. Blue GM, et al. Congenital heart disease: current knowledge about causes and inheritance. Med J Aust. 2012;197(3):155-159.

50. Kalisch-Smith JI, et al. Environmental risk factors for congenital heart disease. Cold Spring Harb Perspect Biol. 2020;12(3):a037234.

51. Beall CM, et al. Natural selection on EPAS1 (HIF2alpha) associated with low hemoglobin concentration in Tibetan highlanders. Proc Natl Acad Sci U S A. 2010;107(25):11459-11464.

52. Moreau JLM, et al. Gene-environment interaction impacts on heart development and embryo survival. Development. 2019;146(4):dev172957.

53. Giussani DA, Davidge ST. Developmental programming of cardiovascular disease by prenatal hypoxia. J Dev Orig Health Dis. 2013;4(5):328-337.

54. Covello KL, et al. HIF-2alpha regulates Oct-4: effects of hypoxia on stem cell function, embryonic development, and tumor growth. Genes Dev. 2006;20(5):557-570

55. Mohyeldin A, et al. Oxygen in stem cell biology: a critical component of the stem cell niche. Cell Stem Cell. 2010;7(2):150-161.

56. Li Y, et al. Genetic lineage tracing of nonmyocyte population by dual recombinases. Circulation. 2018;138(8):793-805

57. Kimura $W$, et al. Hypoxia fate mapping identifies cycling cardiomyocytes in the adult heart. Nature. 2015;523(7559):226-230.

58. Senyo SE, et al. Mammalian heart renewal by pre-existing cardiomyocytes. Nature. 2013;493(7432):433-436

59. Foglia MJ, Poss KD. Building and re-building the heart by cardiomyocyte proliferation. Development. 2016;143(5):729-740.

60. Jopling C, et al. Hypoxia induces myocardial regeneration in zebrafish. Circulation. 2012;126(25):3017-3027.

61. Marin-Juez R, et al. Coronary revascularization 
during heart regeneration is regulated by epicardial and endocardial cues and forms a scaffold for cardiomyocyte repopulation. Dev Cell. 2019;51(4):503-515.

62. Porrello ER, et al. Transient regenerative potential of the neonatal mouse heart. Science. 2011;331(6020):1078-1080.

63. Nakada Y, et al. Hypoxia induces heart regeneration in adult mice. Nature. 2017;541(7636):222-227.

64 . Ye L, et al. Role of blood oxygen saturation during post-natal human cardiomyocyte cell cycle activities. JACC Basic Transl Sci. 2020;5(5):447-460.

65. ClinicalTrials.gov. Hypoxic Conditioning in Heart Failure (hypoxheart). https://clinicaltrials. gov/ct2/show/NCT03537079. Updated March 25, 2020. Accessed July 20, 2021.

66. Savla JJ, et al. The effect of hypoxia on cardiovascular disease: friend or foe? High Alt Med Biol. 2018;19(2):124-130

67. Stanley WC, et al. Myocardial substrate metabolism in the normal and failing heart. Physiol Rev. 2005;85(3):1093-1129.

68. Mirtschink P, Krek W. Hypoxia-driven glycolytic and fructolytic metabolic programs: pivotal to hypertrophic heart disease. Biochim Biophys Acta. 2016;1863(7 pt b):1822-1828.

69. Kolwicz SC Jr., Tian R. Glucose metabolism and cardiac hypertrophy. Cardiovasc Res. 2011;90(2):194-201.

70. Ashrafian $\mathrm{H}$, et al. Metabolic mechanisms in heart failure. Circulation. 2007;116(4):434-448.

71. Huang Y, et al. Cardiac myocyte-specific HIF-1alpha deletion alters vascularization, energy availability, calcium flux, and contractility in the normoxic heart. FASEB J. 2004;18(10):1138-1140.

72. Bekeredjian R, et al. Conditional HIF-1alpha expression produces a reversible cardiomyopathy. PLoS One. 2010;5(7):e11693.

73. Holscher M, et al. Unfavourable consequences of chronic cardiac HIF-1 $\alpha$ stabilization. Cardiovas Res. 2012;94(1):77-86.

74. Wu J, et al. HIF-1 $\alpha$ in heart: protective mechanisms. Am J Physiol Heart Circ Physiol. 2013;305(6):H821-H828.

75. Moslehi J, et al. Loss of hypoxia-inducible factor prolyl hydroxylase activity in cardiomyocytes phenocopies ischemic cardiomyopathy. Circulation. 2010;122(10):1004-1016.

76. Lei L, et al. Hypoxia-inducible factor-dependent degeneration, failure, and malignant transformation of the heart in the absence of the von Hippel-Lindau protein. Mol Cell Biol. 2008;28(11):3790-3803.

77. Ambrose LJ, et al. Investigating mitochondrial metabolism in contracting HL-1 cardiomyocytes following hypoxia and pharmacological HIF activation identifies HIF-dependent and independent mechanisms of regulation. JCardiovasc Pharmacol Ther. 2014;19(6):574-585.

78. Semenza GL. Hypoxia-inducible factor 1: regulator of mitochondrial metabolism and mediator of ischemic preconditioning. Biochim Biophys Acta. 2011;1813(7):1263-1268

79. Zhang H, et al. Mitochondrial autophagy is an HIF-1-dependent adaptive metabolic response to hypoxia. JBiol Chem. 2008;283(16):10892-10903.

80. Kim JW, et al. HIF-1-mediated expression of pyruvate dehydrogenase kinase: a metabolic switch required for cellular adaptation to hypoxia. Cell Metab. 2006;3(3):177-185.

81. Shohet RV, Garcia JA. Keeping the engine primed: HIF factors as key regulators of cardiac metabolism and angiogenesis during ischemia. J Mol Med (Berl). 2007;85(12):1309-1315.

82. Malhotra R, et al. Glucose uptake and adenoviral mediated GLUT1 infection decrease hypoxia-induced HIF-1alpha levels in cardiac myocytes. J Mol Cell Cardiol. 2002;34(8):1063-1073.

83. Schofield CJ, Ratcliffe PJ. Oxygen sensing by HIF hydroxylases. Nat Rev Mol Cell Biol. 2004;5(5):343-354.

84. Koivunen P, et al. Inhibition of hypoxia-inducible factor (HIF) hydroxylases by citric acid cycle intermediates: possible links between cell metabolism and stabilization of HIF. J Biol Chem 2007;282(7):4524-4532.

85. Selak MA, et al. Succinate links TCA cycle dysfunction to oncogenesis by inhibiting HIF-alpha prolyl hydroxylase. Cancer Cell. 2005;7(1):77-85.

86. Dodd MS, et al. Fatty acids prevent hypoxia-inducible factor- $1 \alpha$ signaling through decreased succinate in diabetes. JACC Basic Transl Sci. 2018;3(4):485-498.

87. Luo W, et al. Pyruvate kinase M2 is a PHD3-stimulated coactivator for hypoxia-inducible factor 1 . Cell. 2011;145(5):732-744.

88. Koeppen M, et al. Hypoxia-inducible factor 2-alpha-dependent induction of amphiregulin dampens myocardial ischemia-reperfusion injury. Nat Commun. 2018;9(1):816.

89. Lin $\mathrm{Q}$, et al. Activation of hypoxia-inducible factor-2 in adipocytes results in pathological cardiac hypertrophy. J Am Heart Assoc. 2013;2(6):e000548.

90. Zhang $\mathrm{N}$, et al. The asparaginyl hydroxylase factor inhibiting HIF-1alpha is an essential regulato of metabolism. Cell Metab. 2010;11(5):364-378.

91. Sim J, et al. The factor inhibiting HIF asparaginyl hydroxylase regulates oxidative metabolism and accelerates metabolic adaptation to hypoxia. Cell Metab. 2018;27(4):898-913.

92. Drevytska T, et al. The protective effect of Hif3a RNA interference and HIF-prolyl hydroxylase inhibition on cardiomyocytes under anoxia-reoxygenation. Life Sci. 2018;202:131-139.

93. Heidbreder M, et al. Non-hypoxic induction of HIF-3alpha by 2-deoxy-D-glucose and insulin. Biochem Biophys Res Commun. 2007;352(2):437-443.

94. Semenza GL. Pharmacologic targeting of hypoxia-inducible factors. Annu Rev Pharmacol Toxicol. 2019;59:379-403.

95. Bernhardt WM, et al. Organ protection by hypoxia and hypoxia-inducible factors. Methods Enzymol. 2007;435:221-245.

96. Date T, et al. Expression of constitutively stable hybrid hypoxia-inducible factor-1alpha protects cultured rat cardiomyocytes against simulated ischemia-reperfusion injury. Am JPhysiol Cell Physiol. 2005;288(2):C314-C320.

97. Ockaili R, et al. HIF-1 activation attenuates postischemic myocardial injury: role for heme oxygenase-1 in modulating microvascular chemokine generation. Am J Physiol Heart Circ Physiol. 2005;289(2):H542-H548

98. Kido M, et al. Hypoxia-inducible factor 1-alpha reduces infarction and attenuates progres- sion of cardiac dysfunction after myocardia infarction in the mouse. J Am Coll Cardiol. 2005;46(11):2116-2124.

99. Philipp S, et al. Stabilization of hypoxia inducible factor rather than modulation of collagen metabolism improves cardiac function after acute myocardial infarction in rats. Eur J Heart Fail. 2006;8(4):347-354.

100.Bao W, et al. Chronic inhibition of hypoxia-inducible factor prolyl 4-hydroxylase improves ventricular performance, remodeling, and vascularity after myocardial infarction in the rat. J Cardiovasc Pharmacol.2010;56(2):147-155.

101. Mirtschink P, et al. HIF-driven SF3B1 induces KHK-C to enforce fructolysis and heart disease. Nature. 2015;522(7557):444-449.

102. Lejay $A$, et al. Ischemia reperfusion injury, ischemic conditioning and diabetes mellitus. J Mol Cell Cardiol. 2016;91:11-22.

103. Cerychova R, Pavlinkova G. HIF-1, metabolism, and diabetes in the embryonic and adult heart. Front Endocrinol (Lausanne). 2018;9:460.

104. Montessuit C, Lerch R. Regulation and dysregulation of glucose transport in cardiomyocytes. Biochim Biophys Acta. 2013;1833(4):848-856.

105. Marfella $\mathrm{R}$, et al. Myocardial infarction in diabetic rats: role of hyperglycaemia on infarct size and early expression of hypoxia-inducible factor 1 . Diabetologia. 2002;45(8):1172-1181.

106.Folkman J, et al. Growth and metastasis of tumor in organ culture. Cancer. 1963;16(4):453-467.

107. Semenza GL. Vasculogenesis, angiogenesis, and arteriogenesis: mechanisms of blood vessel formation and remodeling. J Cell Biochem. 2007;102(4):840-847.

108. Potente $\mathrm{M}$, et al. Basic and therapeutic aspects of angiogenesis. Cell. 2011;146(6):873-887.

109. Cooke JP, Losordo DW. Modulating the vascular response to limb ischemia: angiogenic and cell therapies. Circ Res. 2015;116(9):1561-1578.

110.Usui Y, et al. Angiogenesis and eye disease. Annu Rev Vis Sci. 2015;1(1):155-184

111. Krock BL, et al. Hypoxia-induced angiogenesis: good and evil. Genes Cancer. 2011;2(12):1117-1133.

112. Semenza GL. Hypoxia-inducible factor 1 and cardiovascular disease. Annu Rev Physiol. 2014;76:39-56.

113. Resar JR, et al. Hypoxia-inducible factor 1alpha polymorphism and coronary collaterals in patients with ischemic heart disease. Chest. 2005;128(2):787-791.

114. Hlatky MA, et al. Polymorphisms in hypoxia inducible factor 1 and the initial clinical presentation of coronary disease. Am Heart J. 2007;154(6):1035-1042.

115. Duran J, et al. The HIF1A C85T single nucleotide polymorphism influences the number of branches of the human coronary tree. Cardiology. 2012;121(3):156-159.

116. Creager MA, et al. Effect of hypoxia-inducible factor-1alpha gene therapy on walking performance in patients with intermittent claudication. Circulation. 2011;124(16):1765-1773.

117. Rajagopalan $S$, et al. Use of a constitutively active hypoxia-inducible factor-1alpha transgene as a therapeutic strategy in no-option critical limb ischemia patients: phase I dose-escalation experience. Circulation. 2007;115(10):1234-1243. 
118. Semenza GL. Oxygen sensing, homeostasis, and disease. N Engl JMed. 2011;365(6):537-547.

119. Hinkel R, et al. Angiogenetic potential of Ad2/ Hif-1 $\alpha$ /VP16 after regional application in a preclinical pig model of chronic ischemia. Curr Vasc Pharmacol. 2013;11(1):29-37.

120. Kilian EG, et al. Myocardial transfection of hypoxia inducible factor-1alpha via an adenoviral vector during coronary artery bypass grafting. A multicenter phase I and safety study. Circ J. 2010;74(5):916-924.

121. Robich MP, et al. Myocardial therapeutic angiogenesis: a review of the state of development and future obstacles. Expert Rev Cardiovasc Ther. 2011;9(11):1469-1479.

122. Befani C, Liakos P. The role of hypoxia-inducible factor-2 alpha in angiogenesis. JCell Physiol. 2018;233(12):9087-9098.

123. Wiesener MS, et al. Widespread hypoxia-inducible expression of HIF-2alpha in distinct cell populations of different organs. FASEB J. 2003;17(2):271-273.

124. Koh MY, Powis G. Passing the baton: the HIF switch. Trends Biochem Sci. 2012;37(9):364-372.

125. Serocki M, et al. miRNAs regulate the HIF switch during hypoxia: a novel therapeutic target. Angiogenesis. 2018;21(2):183-202.

126. Albadari N, et al. The transcriptional factors HIF-1 and HIF-2 and their novel inhibitors in cancer therapy. Expert Opin Drug Discov. 2019;14(7):667-682.

127. Habib GB, et al. Influence of coronary collateral vessels on myocardial infarct size in humans. Results of phase I thrombolysis in myocardial infarction (TIMI) trial. The TIMI Investigators. Circulation. 1991;83(3):739-746.

128. Sabia PJ, et al. An association between collateral blood flow and myocardial viability in patients with recent myocardial infarction. $N$ Engl J Med. 1992;327(26):1825-1831.

129. Donato M, et al. Protecting the heart from ischemia/reperfusion injury: an update on remote ischemic preconditioning and postconditioning. Curr Opin Cardiol. 2017;32(6):784-790.

130. Heyman SN, et al. Adaptive response to hypoxia and remote ischaemia pre-conditioning: a new hypoxia-inducible factors era in clinical medicine. Acta Physiol (Oxf). 2016;216(4):395-406.

131. Hausenloy DJ, Yellon DM. Ischaemic conditioning and reperfusion injury. Nat Rev Cardiol. 2016;13(4):193-209.

132. Rane S, et al. Downregulation of miR-199a derepresses hypoxia-inducible factor-1alpha and Sirtuin 1 and recapitulates hypoxia preconditioning in cardiac myocytes. Circ Res. 2009;104(7):879-886.

133. Sarkar K, et al. Hypoxia-inducible factor 1 transcriptional activity in endothelial cells is required for acute phase cardioprotection induced by ischemic preconditioning. Proc Natl Acad Sci US A. 2012;109(26):10504-10509.

134. Cai Z, et al. Complete loss of ischaemic preconditioning-induced cardioprotection in mice with partial deficiency of HIF-1 alpha. Cardiovasc Res. 2008;77(3):463-470.

135. Manchenkov T, et al. Novel genes critical for hypoxic preconditioning in zebrafish are regulators of insulin and glucose metabolism. G3 (Bethesda). 2015;5(6):1107-1116.
136. Vogler M, et al. Pre- and post-conditional inhibition of prolyl-4-hydroxylase domain enzymes protects the heart from an ischemic insult. Pflugers Arch. 2015;467(10):2141-2149.

137. Cho YJ, Kim WH. Perioperative cardioprotection by remote ischemic conditioning. Int J Mol Sci. 2019;20(19):E4839.

138. Wang H, et al. Effects of remote ischemic preconditioning in patients undergoing off-pump coronary artery bypass graft surgery. Front Physiol. 2019;10:495.

139. Murry CE, et al. Preconditioning with ischemia: a delay of lethal cell injury in ischemic myocardium. Circulation. 1986;74(5):1124-1136.

140. Heusch G. Critical issues for the translation of cardioprotection. Circ Res. 2017;120(9):1477-1486.

141. Ferns GAA, Heikal L. Hypoxia in atherogenesis. Angiology. 2017;68(6):472-493.

142.Sluimer JC, et al. Hypoxia, hypoxia-inducible transcription factor, and macrophages in human atherosclerotic plaques are correlated with intraplaque angiogenesis. J Am Coll Cardiol. 2008;51(13):1258-1265

143. Vink A, et al. HIF-1 alpha expression is associated with an atheromatous inflammatory plaque phenotype and upregulated in activated macrophages. Atherosclerosis. 2007;195(2):e69-e75.

144.Gao L, et al. The role of hypoxia-inducible factor 1 in atherosclerosis. J Clin Pathol. 2012;65(10):872-876.

145. Harris AJ, et al. HIF-mediated innate immune responses: cell signaling and therapeutic implications. Hypoxia (Auckl). 2014;2:47-58.

146.Kong $\mathrm{T}$, et al. Leukocyte adhesion during hypoxia is mediated by HIF-1-dependent induction of beta2 integrin gene expression. Proc Natl Acad Sci US A. 2004;101(28):10440-10445.

147. Peyssonnaux C, et al. HIF-1alpha expression regulates the bactericidal capacity of phagocytes. J Clin Invest. 2005;115(7):1806-1815.

148. Fluck K, et al. Hypoxia-inducible factor 1 in dendritic cells is crucial for the activation of protective regulatory T cells in murine colitis. Mucosal Immunol. 2016;9(2):379-390.

149. Kohler T, et al. Influence of hypoxia-inducible factor $1 \alpha$ on dendritic cell differentiation and migration. Eur J Immunol. 2012;42(5):1226-1236

150. Naldini A, et al. Hypoxia affects dendritic cell survival: role of the hypoxia-inducible factor- $1 \alpha$ and lipopolysaccharide. J Cell Physiol. 2012;227(2):587-595.

151. Finlay DK, et al. PDK1 regulation of $\mathrm{mTOR}$ and hypoxia-inducible factor 1 integrate metabolism and migration of CD8+ T cells. JExp Med. 2012;209(13):2441-2453.

152. Ivanov II, et al. The orphan nuclear receptor RORgammat directs the differentiation program of proinflammatory IL-17+ T helper cells. Cell. 2006;126(6):1121-1133.

153. Yamagata T, et al. Targeting Th17 effector cytokines for the treatment of autoimmune diseases. Arch Immunol Ther Exp (Warsz). 2015;63(6):405-414.

154.Dang EV, et al. Control of T(H)17/T(reg) balance by hypoxia-inducible factor 1 . Cell. 2011;146(5):772-784.

155. Kojima H, et al. Abnormal B lymphocyte development and autoimmunity in hypoxia-inducible factor $1 \alpha$-deficient chimeric mice. Proc Natl Acad
Sci US A. 2002;99(4):2170-2174.

156. Cho SH, et al. Germinal centre hypoxia and regulation of antibody qualities by a hypoxia response system. Nature. 2016;537(7619):234-238.

157. Lin N, Simon MC. Hypoxia-inducible factors: key regulators of myeloid cells during inflammation. J Clin Invest. 2016;126(10):3661-3671.

158. Stothers CL, et al. Hypoxia-inducible factor-1a regulation of myeloid cells. J Mol Med (Berl). 2018;96(12):1293-1306.

159. Parathath S, et al. Hypoxia is present in murine atherosclerotic plaques and has multiple adverse effects on macrophage lipid metabolism. Circ Res. 2011;109(10):1141-1152.

160. Bogomolova AM, et al. Hypoxia as a factor involved in the regulation of the apoA-1, ABCA1, and complement C3 gene expression in human macrophages. Biochemistry (Mosc). 2019;84(5):529-539.

161. Ugocsai P, et al. HIF-1beta determines ABCA1 expression under hypoxia in human macrophages. Int J Biochem Cell Biol. 2010;42(2):241-252.

162.Aarup A, et al. Hypoxia-inducible factor-10 expression in macrophages promotes development of atherosclerosis. Arterioscler Thromb Vasc Biol. 2016;36(9):1782-1790.

163. Liu ML, et al. Cholesterol enrichment of human monocyte/macrophages induces surface exposure of phosphatidylserine and the release of biologically-active tissue factor-positive microvesicles. Arterioscler Thromb Vasc Biol. 2007;27(2):430-435.

164. Mills EL, et al. Succinate dehydrogenase supports metabolic repurposing of mitochondria to drive inflammatory macrophages. Cell. 2016;167(2):457-470.

165. Corcoran SE, O’Neill LA. HIF1 $\alpha$ and metabolic reprogramming in inflammation. JClin Invest. 2016;126(10):3699-3707.

166. Werno C, et al. Knockout of HIF-1 $\alpha$ in tumor-associated macrophages enhances M2 polarization and attenuates their pro-angiogenic responses. Carcinogenesis. 2010;31(10):1863-1872.

167. Takeda N, et al. Differential activation and antagonistic function of HIF- $\alpha$ isoforms in macrophages are essential for NO homeostasis. Genes Dev. 2010;24(5):491-501.

168. Osada-Oka M, et al. VEGF-enhanced proliferation under hypoxia by an autocrine mechanism in human vascular smooth muscle cells. J Atheroscler Thromb. 2008;15(1):26-33.

169. Osada-Oka M, et al. Hypoxia stimulates the autocrine regulation of migration of vascular smooth muscle cells via HIF-1alpha-dependent expression of thrombospondin-1. J Cell Biochem. 2008;104(5):1918-1926.

170.Allahverdian S, et al. Smooth muscle cell fate and plasticity in atherosclerosis. Cardiovasc Res. 2018;114(4):540-550.

171. Baumer Y, et al. CD98 regulates vascular smooth muscle cell proliferation in atherosclerosis. Atherosclerosis. 2017;256:105-114.

172. Kyotani Y, et al. Proliferative pathways of vascular smooth muscle cells in response to intermittent hypoxia. Int J Mol Sci. 2019;20(11):2706.

173. Fu H, et al. Hypoxia stimulates the expression of macrophage migration inhibitory factor in human vascular smooth muscle cells via HIF-1alpha 
dependent pathway. BMC Cell Biol.2010;11:66.

174. Balogh E, et al. Hypoxia triggers osteochondrogenic differentiation of vascular smooth muscle cells in an HIF-1 (Hypoxia-Inducible Factor 1)-dependent and reactive oxygen species-dependent manner. Arterioscler Thromb Vasc Biol. 2019;39(6):1088-1099.

175. Akhtar S, et al. Endothelial hypoxia-inducible factor-1 $\alpha$ promotes atherosclerosis and monocyte recruitment by upregulating MicroRNA-19a. Hypertension. 2015;66(6):1220-1226.

176. Tang N, et al. Loss of HIF-1alpha in endothelial cells disrupts a hypoxia-driven VEGF autocrine loop necessary for tumorigenesis. Cancer Cell. 2004;6(5):485-495.

177. Ihling C, et al. Coexpression of endothelin-converting enzyme- 1 and endothelin- 1 in different stages of human atherosclerosis. Circulation. 2001;104(8):864-869.

178. Pasterkamp G, et al. Atherosclerotic arterial remodeling and the localization of macro- phages and matrix metalloproteases 1, 2 and 9 in the human coronary artery. Atherosclerosis. 2000;150(2):245-253.

179. Celletti FL, et al. Vascular endothelial growth factor enhances atherosclerotic plaque progression. Nat Med. 2001;7(4):425-429.

180. Hutter R, et al. Macrophages transmit potent proangiogenic effects of oxLDL in vitro and in vivo involving HIF-1 $\alpha$ activation: a novel aspect of angiogenesis in atherosclerosis. J Cardiovasc Transl Res. 2013;6(4):558-569.

181. Jin F, et al. Impairment of hypoxia-induced angiogenesis by LDL involves a HIF-centered signaling network linking inflammatory $\mathrm{TNF} \alpha$ and angiogenic VEGF. Aging (Albany NY). 2019;11(2):328-349.

182.Van der Wall H, Palmer A. On the AJR viewbox. Monomelic spread of metastatic disease due to proximal deep venous thrombosis. AJR Am J Roentgenol. 2006;186(6):1797-1799.

183. Packer M. Mutual antagonism of hypoxia- inducible factor isoforms in cardiac, vascular, and renal disorders. JACC Basic Transl Sci. 2020;5(9):961-968.

184. FibroGen. FibroGen Announces FDA Advisory Committee to Review Roxadustat New Drug Application Tentatively Scheduled for July 15, 2021. https://investor.fibrogen.com/news-releases/ news-release-details/fibrogen-announces-fdaadvisory-committee-review-roxadustat-new. Updated April 16, 2021. Accessed July 20, 2021.

185. Ghosh MC, et al. Therapeutic inhibition of HIF$2 \alpha$ reverses polycythemia and pulmonary hypertension in murine models of human diseases. Blood. 2021;137(18):2509-2519.

186.Choueiri TK, et al. Targeting the HIF2VEGF axis in renal cell carcinoma. Nat Med. 2020;26(10):1519-1530.

187. Holscher M, et al. Cardiomyocyte-specific prolyl-4-hydroxylase domain 2 knock out protects from acute myocardial ischemic injury.J Biol Chem. 2011;286(13):11185-11194. 